\title{
Low level exposures to organophosphorus esters may cause neurotoxicity
}

\author{
Goran A. Jamal ${ }^{\mathrm{a}, *}$, Stig Hansen ${ }^{\mathrm{b}}$, Peter O.O. Julu ${ }^{\mathrm{a}}$ \\ ${ }^{a}$ Division of Neurosciences, Imperial College of Science, Technology and Medicine, University of London, London, UK \\ ${ }^{\mathrm{b}}$ South Glasgow University Hospitals NHS Trust, Glasgow, UK
}

\begin{abstract}
A large number of published studies support the notion that long term, low level (LTLL) exposure to organophosphorus (OP) esters may cause neurological and neurobehavioral effects. In order to differentiate these from other effects of OP such as the acute cholinergic episodes, intermediate syndrome and organophosphate induced delayed neuropathy (OPIDN), the term Chronic Organophosphate Induced Neuropsychiatric Disorder (COPIND) will be used purely for the ease of reference. The question addressed in this particular review is whether LTLL exposure to OP may produce neurotoxicity. The profile and the degree of overlap of the various components of COPIND have been addressed elsewhere and description of the possible mechanisms for COPIND is outside the scope of this article. COPIND can be classified under two headings; those produced following one or more acute clinical cholinergic episodes, and those produced without such preceding attacks. With regards to the first group, there are a total of 11 studies, all of which support the existence of a positive link between exposure to OP and neurotoxicity; six of these studies comprise descriptions of large numbers of cases without controls while five additional studies employ controls. Appearance of neurotoxicity does not seem to be related to the number or the intensity of acute cholinergic attacks. With regards to the second group, three types of studies can be identified. Firstly, there are five studies using experimental animals, all of which showed a positive link between OP and neurotoxicity. Secondly, a total of seven case studies without controls, some involving large numbers of patients, concluded that there is a positive link between OP and neurotoxicity. Thirdly, 19 studies investigated such a link using cases and control groups. Of these, 15 studies (about $80 \%$ ) showed a positive link and only four failed to identify any link between OP and neurotoxicity. Annotation of all the 19 studies according to ideal set of criteria showed that only a few of these comply with the rules of excellence and all of these few showed a positive link. Furthermore, the only study carried out blind without the identification of subjects or controls, showed a positive link between OP and neurotoxicity. This blind study estimated the overall incidence of a form of neurotoxicity in people exposed to OP to be about 40 times higher than in the general population. The type of neurological involvement was unique and different from OP induced syndromes previously described. The profile of the neurological involvement was similar to that in COPIND whether or not preceded by acute cholinergic episodes, thus providing further evidence that these two neuropathies probably share a similar mechanism. There is a characteristic pattern of involvement of 15 functional indices of the autonomic nervous system examined in our laboratory. There are, in addition, preferential anatomical sites of target organs affected, selective preservation of
\end{abstract}

\footnotetext{
* Corresponding author. Present address: Department of Neurology, Central Middlesex Hospital, Park Royal, London NW10 7NS, UK. Tel.: +44-20-8453-2247; fax: +44-20-8866-8567

E-mail address: gji151283@aol.com (G.A. Jamal).
} 
cholinergic function within the same neuropathy-positive site, and evidence of mal-function of cardiac chemoreceptors in patients exposed to OP. The peripheral nerve involvement in OP exposure is predominantly sensory in nature affecting both small and large fibre populations. Neurobehavioral involvement of mainly cognitive dysfunction and other features are also described in other studies. The weight of current evidence is therefore very much in favor of the motion that chronic low-level exposure to OP produces neurotoxicity. Criticisms levelled against this motion are unfounded and probably misconceived.

(C) 2002 Elsevier Science Ireland Ltd. All rights reserved.

Keywords: Organophosphates; Insecticides; Neurological; Neurobehavioral; Neurotoxicity; Psychiatric; Electroencephalography; Electromyography; Single fibre EMG; Jitter; Nerve conduction; Neurophysiology; Quantitative sensory tests; Autonomic nervous system; Evoked potentials; Neuromuscular junction; Cognitive dysfunction; Neuropathy

\section{Introduction}

Exposure to organophosphorus (OP) esters can cause several syndromes including acute cholinergic clinical episodes, the so-called Intermediate syndrome, organophosphate induced delayed neuropathy (OPIDN) and chronic neurological effects. Acute toxicity is produced by irreversible inactivation of the enzyme cholinesterases, the exact mechanism of the intermediate syndrome is not understood while the OPIDN is claimed to be 'marked' by the inhibition and subsequent ageing (dealkylation) of a protein enzyme in nerve cells called neuropathy target esterase (NTE). The ability to produce OPIDN is not even related to the degree of inhibition of AchE and there is no indication that the intermediate syndrome is related to the cholinergic effect of OP compounds. It took the medical and scientific body more than 50 years to recognise OPIDN despite its dramatic nature of clinical presentation.

Chronic neurological effects have been reported to occur either following one or more attacks of acute cholinergic episodes or following long-term, low-level (LTLL) exposure to OP compounds. In order to differentiate the chronic neurological effects from the rest of the OP syndromes, the term Chronic Organophosphate Induced Neuropsychiatric Disorder (COPIND) is used for ease of reference. The remit of this review is confined to providing affirmative evidence to the title statement that low-level exposure to OP esters may cause neurotoxicity. It is not the remit of this article to describe the profile of the chronic toxicity or to discuss the possible underlying mechanisms of such chronic toxicity. These have been described elsewhere (Jamal, 1997) but will be mentioned briefly, given the limited space.

\section{Review of studies in the literature}

Studies concerning the chronic effects of OP esters are discussed in this review under two different headings; studies of COPIND following one or more acute clinical cholinergic episodes and COPIND without preceding cholinergic attacks.

\subsection{COPIND following acute cholinergic episodes}

All the studies identified in the literature in this respect reach similar conclusion that there is a positive link between exposure and neurotoxicity. These studies can be divided into two groups. There are six studies which describe a large number of cases with a history of acute cholinergic episodes which developed long-term chronic neurotoxicity (Table 1) and these studies did not utilise control subjects. Table 2 shows a further five studies, which used controls for comparison and all the five studies concluded that there are positive links between OP exposures and chronic neurotoxicty. Analysis of all the above 11 studies show that neither the incidence nor the severity of development of chronic neurotoxicity had any relation with either the number nor the severity of the acute cholinergic episodes. In some of the cases described, the acute episodes were so mild that they escaped clinical detection (Kaplan et al., 1993; Jamal et al., 2001). 
Table 1

Studies of chronic OP neurotoxicity following acute episode(s) that used no matched control groups

\begin{tabular}{|c|c|c|c|c|}
\hline Reference & Exposed group & Parameters studied & Link & Controls \\
\hline Holms, 1955 & Workers & EEG & + & - \\
\hline Tabershaw and Cooper, 1966 & Workers & Psychiatry & + & - \\
\hline Korsak and Sato, 1977 & Workers & $\begin{array}{l}\text { EEG } \\
\text { Psychometric }\end{array}$ & $\begin{array}{l}+ \\
+\end{array}$ & - \\
\hline Hirschberg and Lerman, 1984 & Workers & $\begin{array}{l}\text { EEG } \\
\text { Psychiatry }\end{array}$ & $\begin{array}{l}+ \\
+\end{array}$ & - \\
\hline Kaplan et al., 1993 & Mixed & $\begin{array}{l}\text { Neurology } \\
\text { Neurophysiology } \\
\text { Psychometric }\end{array}$ & $\begin{array}{l}+ \\
+ \\
+\end{array}$ & - \\
\hline Callender et al., 1994 & Workers & $\begin{array}{l}\text { Neurology } \\
\text { SPECT scan }\end{array}$ & $\begin{array}{l}+ \\
+\end{array}$ & - \\
\hline
\end{tabular}

\subsection{COPIND without previous acute cholinergic episodes}

Three types of studies studies investigated the link between LTLL subclinical exposure and chronic neurotoxicity:

1) Five studies in experimental animals all showed a positive link between OP exposure and neurotoxicity (Table 3). These studies looked at OP effects on the central as well as the peripheral nervous systems and all were of very high quality with proper experimental controls.

2) Seven studies conducted in apparently healthy groups of individuals, who were still working at the time of the study, all concluded that there was a positive link between LTLL OP exposure and neurotoxicity (Table 4). Large numbers of cases were studied but without matched controls or any other kind of controls. The procedures included assessment of the central and peripheral nervous systems and the findings were judged against predetermined criteria of abnormality for the particular tests or neuropathy assessments employed.

3) Nineteen studies conducted on human subjects of different occupations and in which matched controls were used (Table 5). Of these, 15 (about 80\%) demonstrated and concluded that there was a positive link

Table 2

Studies of chronic OP neurotoxicity following acute episode(s) that used matched control groups

\begin{tabular}{|c|c|c|c|c|}
\hline Reference & Exposed group & Parameters studied & Link & Controls \\
\hline Savage et al., 1988 & Workers & $\begin{array}{l}\text { Psychometric } \\
\text { Neuronal necrosis }\end{array}$ & $\begin{array}{l}+ \\
+\end{array}$ & Matched \\
\hline Rosenstock et al., 1991 & Workers & Psychometric & + & Matched \\
\hline Steenland et al., 1994 & Mixed & $\begin{array}{l}\text { Neurology } \\
\text { Neurophysiology } \\
\text { Psychometric }\end{array}$ & $\begin{array}{l}+ \\
+ \\
+\end{array}$ & Matched \\
\hline McConnell et al., 1994 & Workers & Neurophysiology & + & Matched \\
\hline Jamal et al., 2001 & Farmers & $\begin{array}{l}\text { Neurology } \\
\text { Neurophysiology }\end{array}$ & $\begin{array}{l}+ \\
+\end{array}$ & Matched \\
\hline
\end{tabular}


Table 3

Studies of chronic OP neurotoxicity following LTLL exposure using experimental animals

\begin{tabular}{lllll}
\hline Reference & Exposed animals & Parameters studied & Link & Controls \\
\hline Burchfiel et al., 1976 & Primates & EEG & + & control and pre-exp EEG \\
Duffy and Burchfiel, 1980 & Rhesus monkeys & EEG & + & Non-exposed \\
Kelly et al., 1994 & Mice & EPP jitter & + & Self control \\
Kelly et al., 1997 & Mice & EPP jitter & + & Self control \\
Prendergast et al., 1997 & Rats & Spatial learning & + & Self control \\
\hline
\end{tabular}

between LTLL exposure to OP esters and the development of chronic neurotoxicity. Only four studies failed to demonstrate such a link but these are relatively old and most of them can be criticised for their design and strict relevance to the question. For example, in the study by Maizlish et al. (1987), subjects were only exposed for the duration of 39 days in total, which is hardly relevant to long-term exposure. Three of the four studies with negative results looked at small numbers in addition to other methodological shortcomings. All these four negative studies except one, looked almost exclusively at psychometric aspects, indicating the restricted number of neuropathy parameters examined in the studies.
We have attempted to annotate these 19 studies of group three using the following criteria: (1) Subjects selected represented the population studied i.e. no selection bias; (2) the controls used were appropriate and matched; (3) the sample size was adequate and the statistics used were appropriate; (4) the study design was cross-sectional; (5) examiner groups worked blind of each other's findings; and (6) all examiners were blind to the identity and category of subjects, that is whether subjects were controls or otherwise. Out of the total of 19, only four studies fulfilled the first four of the rules above and these are: Stephens et al. (1995), Cole et al. (1997), Fiedler et al. (1997), Horowitz et al. (1999). One study fulfilled the first five rules; Jamal et al. (2001) and only one study fulfilled all the six rules above, the study by

Table 4

Studies in humans of chronic OP neurotoxicity following LTLL exposure in which no matched control groups were included

\begin{tabular}{|c|c|c|c|c|}
\hline Reference & Exposed group & Parameters studied & Link & Controls \\
\hline Gershon and Shaw, 1961 & Workers/scientists & Psychiatry & + & - \\
\hline Dille and Smith, 1964 & Workers & Psychiatry & + & - \\
\hline Metcalf and Holmes, 1969 & Workers & $\begin{array}{l}\text { Psychometric } \\
\text { EEG }\end{array}$ & $\begin{array}{l}+ \\
+\end{array}$ & High/low dose \\
\hline Korsak and Sato, 1977 & Workers & $\begin{array}{l}\text { Psychometric } \\
\text { EEG }\end{array}$ & $\begin{array}{l}+ \\
+\end{array}$ & - \\
\hline Burger et al., 1991 & Workers & $\begin{array}{l}\text { Neurology } \\
\text { Neurophysiology }\end{array}$ & $\begin{array}{l}+ \\
+\end{array}$ & - \\
\hline Ahmed and Davies, 1997 & Farmers & $\begin{array}{l}\text { Psychiatry } \\
\text { Neurophysiology }\end{array}$ & $\begin{array}{l}+ \\
+\end{array}$ & - \\
\hline Amr, 1999 & Applicators (300)/Formulators (300) & $\begin{array}{l}\text { Neurology }(40 \%) \\
\text { Neurophysiology }(40 \%) \\
\text { EEG }(25 \%) \\
\text { Psychiatry }(40 \%)\end{array}$ & $\begin{array}{l}+ \\
+ \\
+ \\
+\end{array}$ & - \\
\hline
\end{tabular}


Table 5

Studies of human chronic OP neurotoxicity following LTLL exposure in which matched control groups were included

\begin{tabular}{|c|c|c|c|c|}
\hline Reference & Exposed group & Parameters studied & Link & Controls \\
\hline Stoller et al., 1965 & Workers & Psychometric & - & Non-exposed \\
\hline Rodnitzky et al., 1975 & Sprayers & Psychometric & - & Non-exposed \\
\hline Levin et al., 1976 & Sprayers & Psychiatry & + & Non-exposed \\
\hline Duffy et al., 1979 & Workers & EEG +(MultivarAnal) & + & Non-exposed \\
\hline Maizlish et al., 1987 & Workers & Psychometric & - & Non-exposed \\
\hline Misra et al., 1994 & Applicators & $\begin{array}{l}\text { Neurology }+ \\
\text { Psychometric }+ \\
\text { P300 }(\text { CEP })+\end{array}$ & $\begin{array}{l}+ \\
+ \\
+\end{array}$ & Non-exposed and matched \\
\hline Ames et al., 1995 & Applicators & $\begin{array}{l}\text { Psychometric - } \\
\text { Neurophysiology - }\end{array}$ & $\begin{array}{l}- \\
-\end{array}$ & Non-exposed \\
\hline Stokes et al., 1995 & Applicators & $\begin{array}{l}\text { Neurology }+ \\
\text { Neurophysiology }+\end{array}$ & $\begin{array}{l}+ \\
+\end{array}$ & Non-exposed \\
\hline Stephens et al., 1995 & Farmers & $\begin{array}{l}\text { Neurobehavioral }+ \\
\text { Psychometric }+\end{array}$ & $\begin{array}{l}+ \\
+\end{array}$ & Non-exposed quarry workers \\
\hline Beach et al., 1996 & Farmers & Neurology + & + & Quarry workers \\
\hline Parron et al., 1996 & Farmers & Psychiatry + & + & Non-exposed \\
\hline Cole et al., 1997 & Applicators & $\begin{array}{l}\text { Neurobehavioral }+ \\
\text { Psychometric }+\end{array}$ & $\begin{array}{l}+ \\
+\end{array}$ & Non-exposed \\
\hline Fiedler et al., 1997 & Farmers & $\begin{array}{l}\text { Neurobehavioral - } \\
\text { Psychometric }+\end{array}$ & $\begin{array}{l}- \\
+\end{array}$ & Non-exposed \\
\hline Al-Shehab et al., 1998 & Workers & $\begin{array}{l}\text { Neurology }+(68 \%) \\
\text { Neurophysiology }+\end{array}$ & $\begin{array}{l}+ \\
+\end{array}$ & Non-exposed \\
\hline Horowitz et al., 1999 & Applicators & $\begin{array}{l}\text { Neurology }+(44 \%) \\
\text { Neurophysiology }+\end{array}$ & $\begin{array}{l}+ \\
+\end{array}$ & Non-exposed \\
\hline Kilburn, 1999 & Exposed (indoor) & $\begin{array}{l}\text { Neurology }+ \\
\text { Psychometric }+ \\
\text { Neurobehavioral }+\end{array}$ & $\begin{array}{l}+ \\
+ \\
+\end{array}$ & Non-exposed \\
\hline Davies et al., 1999 & Farmers & $\begin{array}{l}\text { Psychiatry }+ \\
\text { Neurobehavioral }+\end{array}$ & $\begin{array}{l}+ \\
+\end{array}$ & Non-exposed \\
\hline IOM/INS 2001 & Farmers & $\begin{array}{l}\text { Neurology }+ \\
\text { Neurophysiology }+ \\
\text { Neurobehavioral }+ \\
\text { Psychometric }+\end{array}$ & $\begin{array}{l}+ \\
+ \\
+ \\
+\end{array}$ & Non-exposed farmers, quarry workers and blind \\
\hline Jamal et al., 2001 & Farmers & $\begin{array}{l}\text { Neurology }+ \\
\text { Neurophysiology }+ \\
\text { Neurobehavioral }+\end{array}$ & $\begin{array}{l}+ \\
+ \\
+\end{array}$ & Non-exposed farmers and blind \\
\hline
\end{tabular}

Pilkington et al. (1999). All of these high quality studies showed evidence of a positive link between LTLL exposure to OP esters and chronic neurotoxicity. The most accurate study available to date estimated the overall incidence of one form of neurotoxicity, distal axonal peripheral neuropa- thy, to be about 40 times in people exposed to OP compared to the incidence in the general population (Pilkington et al., 1999). This involved 612 subjects exposed to OP and they were compared with a large group of unexposed subjects of the same occupational group as well as with another 
large group of control subjects belonging to a different occupational group but with a similar physical effort, socio-economic background and geographical location. The study included a complex OP exposure assessment model, a detailed field study followed by a comprehensive and exhaustive hospital-based examination and investigation. All investigators were kept completely blind of the identity and category of subjects, their exposure history or the outcome of the field study. The investigators were also blind to each other's findings. The study concluded that there was a positive link between LTLL exposure to OP esters and chronic neurotoxicity. The study also provided important insight into the profile of neurotoxicity, which confirmed earlier findings and showed that there was a positive correlation between abnormal neurological tests and evidence of anxiety and depression in patients exposed to OP. In another study (Jamal et al., 2001), the neuropathy profile confirmed earlier observations (Kaplan et al., 1993; Steenland et al., 1994; McConnell et al., 1994; Horowitz et al., 1999; Pilkington et al., 1999) that this neuropathy linked to LTLL exposure to OP, unlike OPIDN, was predominately involving the sensory nerve fibres and affected both small and large fibre populations. This neuropathy profile linked with LTLL exposure to OP was also compared with another one seen in chronic neurotoxicity following one or more acute cholinergic episodes (Jamal et al., 2001). The two neuropathy-profiles were found to be similar, though generally more pronounced in the group where cholinergic attacks preceded neuropathy thus providing further evidence that the neuropathies linked with OP exposure probably have similar pathophysiology.

\subsection{The objective neurological evidence of $O P$ neurotoxicity}

A variety of objective neurological and neuropsychometric tests and procedures have been used to investigate the link between LTLL exposure to $\mathrm{OP}$ esters and chronic neurotoxicity. These include psychometric tests, EEG, neurological examination, nerve conduction studies, needle EMG studies, quantitative sensory testing, neuromuscular jitter testing, cognitive evoked potentials, SPECT scanning. Other abnormalities found included speech abnormality, extrapyramidal features, frontal lobe syndrome and organic psychiatric manifestations. Of all these parameters and the groups of tests listed above, a slight inconsistency was found in the literature in only the first four, nevertheless, the absolute majority of studies have demonstrated clear and consistent abnormal findings in patients exposed to OP. A battery of Psychometric tests is sophisticated, the sensitivity is not high and different methods are used which may explain the apparent inconsistency of the results of such studies. Inconsistencies are also encountered in conditions where there is no argument of the presence of psychological changes, for example, in post-traumatic head injury patients. Studies using the remaining neurological parameters listed above all demonstrated clear abnormalities in patients exposed to OP. As for the EEG, it is generally agreed that computerbased EEG analysis always detects abnormality. As for nerve conduction studies, care must be taken in the choice of the nerves and methods used. Bedside neurological examination alone is not always sensitive enough to be used to obtain sufficient evidence of neurological dysfunction.

\subsection{The autonomic evidence of $O P$ neurotoxicity}

Recent advances in clinical examination of the autonomic nervous system (Julu et al., 1997b, 2000, 2001; Moran et al., 2001) can now allow profiling of target organ functions in various diseases. We have carried out target-organ orientated examination of the autonomic nervous system initially in 15 patients with LTLL exposure to OP (Julu et al., 1997a), but have now expanded it to 40 patients with exposure periods ranging between 5 and 25 years (Julu et al., 1997 unpublished data). These patients were referred to us for examination of autonomic function because their symptoms gave the clinical impression of COPIND. A total of 15 indices of autonomic functions were examined according to predetermined criteria of normality (Julu et al., 1997b, 2000) and autonomic target organs situated in the skin, large blood vessels including the heart, the brainstem, 
splanchnic bed and skeletal muscles were covered in this clinical assessment. A unique combination of the type of target organs affected immerged among the 40 patients, quite different from what we have observed in other diseases during our regular clinical autonomic assessments. What was also unique among OP exposed patients was that certain cholinergic functions were selectively preserved; for example, the sudomotor function in the skin and respiratory modulation of cardiac vagal tone in the bulbar reticular formation in the brainstem were often not affected and yet other functions that do not require cholinergic nerves in the same anatomical sites were abnormal. It is well known that chronic low level of anticholinesterase activity protects cholinergic synapses from episodic large anticholinesterase poisoning, but could it at the same time damage non-cholinergic synapses in the same area? This is a strong possibility given the evidence from our patients chronically exposed to LTLL of OP.

The anatomical sites where autonomic targetorgans were most often affected were the skin, the large blood vessels including the heart and the brainstem. Each of these commonly affected anatomical sites has a unique feature, for example, there is selective preservation of sudomotor function in the skin mentioned above. In the heart, there is non-vagal bradycardia in most patients, the type evoked by stimulation of sub-endocardial chemoreceptors using noxious chemicals (Eckberg et al., 1974). It is suggestive of malfunction of these cardiac chemoreceptors in patients with LTLL exposure to OP. In the brainstem, there is a selective central parasympathetic abnormality resulting in a low resting cardiac vagal tone in a system where monoaminergic function is required (Jordan, 1995), while the vasodepressor function of the baroreflex and respiratory modulation of cardiac vagal tone where there is a known participation of cholinergic neurones (Jordan, 1995) are often both normal. This observation in the brainstem is consistent with the central nervous system involvement in chronic exposure to $\mathrm{OP}$, featuring characteristic neurobehavioral manifestations mainly involving the cognitive function and other features (Ahmed and Davies, 1997;
Davies et al., 1999) known to be influenced by monoaminergic neurones.

The above studies provide a body of evidence that LTLL exposure to OP selectively damages certain autonomic synapses or nerves.

\subsection{Answers to counter arguments}

The following arguments put forth against the association of LTLL to OP with neurotoxicity are invalid and weak for these reasons.

\subsubsection{Studies suffer from selection bias}

As annotated above, there are some extremely powerful and well-designed studies concluding that there is a link.

\subsubsection{There is lack of follow up as to what happens in the long term after cessation of exposure}

This is not an argument as such against the existence of chronic neurotoxicity. We do agree on the necessity of such studies. We have done some work in this regard and our early results indicate that some patients show clear improvement after cessation of exposure and peripheral neurophysiological parameters may even normalise, while other patients do not. This is typically seen in other chronic toxic neuropathies such as those caused by lead and thallium.

\subsubsection{The mechanism of chronic toxicity is not known}

There are many well established neurological diseases for which the mechanism is not known such as Motor Neurone Disease (MND), Parkinson disease, migraine, etc. Furthermore, the mechanism of intermediate syndrome of OP is also unknown but nobody doubts its existence. There are several possible postulated mechanisms to explain chronic toxicity, but their discussion is beyond the scope of this article (Table 6).

\subsubsection{Studies fail to establish dose-response relationship}

It is much more difficult to measure exposure in cases of LTLL exposure to any chemical and OP is not different in this regard. A number of complicating factors, which make exposure assessment 
Table 6

Possible mechanisms of chronic OP neurotoxicity

\begin{tabular}{ll}
\hline Proposed mechanism & Suggesting authors and
\end{tabular}
papers

Prolonged AChE inhibition

Duffy and Burchfiel, 1980

Abnormal cerebral circulation

Duffy and Burchfiel, 1980

Long term pre-synaptic disorder and variable synaptic safety factor

Duffy and Burchfiel, 1980

Baker and Sedgwick, 1996

Jamal, 1997

Albuquerque, 1998

Disturbed cellular protein turnover Berman, 1992 and trans-membrane signaling

Damaged proteins other than Ach and NTE

Jamal, 1997

Glynn, 2000

Alteration of cytoskeletal proteins: microtubules, neurofilament triplet proteins and MAP

Abou-Donia et al., 1996

Abou-Donia and Garretson, 2000

CNS receptor deregulation

Corrigan et al., 1994

Albuquerque, 1998

Davies et al., 1999

Table 7

Factors influencing estimation of chronic low level exposure dose

1. Quantity

Size of individual episode exposure Number of cumulated episodes of exposure

2. Time factor Duration of individual episode exposure Overall years of exposure Frequency of exposure (per year) Intervals between exposures

3. Use and quality of protective equipment

4. Combination exposure or 'cocktail effect' exposure to other chemicals

5. Exposure to impurities

6. Other factors (e.g. physical and mental stress, state of blood-brain barrier)

extremely difficult (Table 7, may be responsible for absence of dose-response relationship in some studies. Furthermore, the high quality studies did show a dose-response relationship (Stephens et al., 1995; Pilkington et al., 1999).

\subsubsection{Studies describe electrophysiological effects of uncertain significance}

Abnormal neurophysiology is a marker for abnormal function. The correlation of its various parameters with symptoms or measurement of the severity of neurological involvement are different matters altogether and should not be confused.

\subsubsection{Neurotoxicity even if detected is subtle and in some cases not associated with signs}

The parameters used are markers of dysfunction and they do not necessarily measure severity. It is extremely difficult to measure the severity of some crippling symptoms such as fatigue, changes in concentration, disturbances of memory, nausea, dizziness, sweating and many other symptoms. Furthermore, all the studies done compare a 'healthy and working' occupational group with controls and the studies are therefore not designed to look at severity anyway.

\subsubsection{Neuropathy does not improve, even several} months after cessation of exposure

This is typical of and evidence for chronic neurotoxicity. Even demyelinating neuropathies may take up to 30 months to improve, and improvement of most axonal neuropathies is less consistent, with some improving, but others not.

\subsubsection{Reports of psychogenic tests show inconsistent results and changes may be in the opposite direction}

The psychometric tests are a battery of various tests that are carried out according to different protocols. The overall picture is important and this is consistent in the vast majority of the studies. Occasional inconsistencies are found in some of the studies, but this may be due to different methodologies or variation in subject selection. Such variations are also encountered in psychometric tests in relation to other entities, such as 
head injury, in which there are well-recognised psychometric changes.

\section{Conclusion}

- Each and every study available in the literature concludes that chronic neurotoxicity can follow one or more acute clinical cholinergic episodes. The development of chronic neurotoxicity seems to be unrelated to the number or the severity of the acute cholinergic attacks.

- With regards to the relationship between long term low level exposure to OP (with no history of preceding acute cholinergic episodes) and development of chronic neurotoxicity, the following conclusions can be made: All studies done so far on experimental animals (five in total) show positive link; All human studies conducted without controls (seven in total) concluded a positive link; About $80 \%$ of studies on humans which used controls (19 in total) showed a positive link. Furthermore, in the last group, studies that ranked high in quality using set criteria, all showed a positive link.

- There seems to be a characteristic profile of involvement of the various neurological parameters in chronic neurotoxicity and this profile is similar in both types of chronic toxicity (i.e. whether or not preceded by acute cholinergic episodes).

- The weight of evidence in the literature is heavily in favor of the motion.

- Criticisms levelled against the motion are not valid.

\section{References}

Abou-Donia, M.B., Garretson, L.K., 2000. Detection of neurofilament antibodies in human serum following chemically induced neurologic disorder. Environ. Epidemiol. Toxicol. 2, 37-41.

Abou-Donia, M.B., Wilmarth, K.R., Abdel-Rahman, A.A., Jenson, K.F., Oheme, F.W., Kurt, T., 1996. Increased neurotoxicity following cocurrent exposure to pyridostigmine bromide, DEET, and chlorpyrifos. Fundam. Appl. Toxicol. 34, 201-222.
Ahmed, G.M., Davies, D.R., 1997. Chronic organophosphate exposure: towards the definition of a neuropsychiatric syndrome. J. Nutr. Environ. Med. 7, 169-176.

Albuquerque, E.X., 1998. Molecular targets for organophosphates in the central nervous system. Government Reports Announcements Index, 2.

Al-Shehab, A., Jaghabir, M., Hmarasheh, F., Wazwaz, M., Abdulmajid, A., 1998. Peripheral neuropathies among workers exposed to insecticides. Birasat. Med. Biolog. Sci. $25,46-52$.

Ames, R., Steenland, K., Jenkins, B., Chrislop, D., Russo, J., 1995. Chronic neurologic sequelae to cholinesterase inhibition among agricultural pesticide applicators. Arch. Environ. Health 50, 440-443.

Amr, M.M., 1999. Pesticide monitoring and its health problems in Egypt, a Third World Country. Toxicol. Lett. 107, 1-13.

Baker, D.J., Sedgwick, E.M., 1996. Single fibre electromyographic changes in man after organophosphate exposure. Hum. Experiment. Toxicol. 15, 369-375.

Beach, J.R., Spurgeon, A., Stephens, R., Heafield, T., Calvert, I.A., et al., 1996. Abnormalities on neurological examination among sheep farmers exposed to organophosphate pesticides. Occup. Environ. Med. 53, 520-525.

Berman, H.A., 1992. Sites and mechanisms of organophosphate toxicity. Crisp Data Base NIH.

Burchfiel, J.L., Duffy, F.N., Sim, V.M., 1976. Persistent effects of sarin and dieldrin upon the primate EEG. Toxicol. Appl. Pharmacol. 35, 365-379.

Burger, M., Alonzo, C., Heuhs, L., Laborde, A., Lqcuague, J., Alfonso, L., 1991. Poly neuropathy due to organophosphorus pesticides [French]. Arch. Mal. Prof. (Paris) 52, $37-$ 38.

Callender, T.J., Morrow, L., Subramanian, K., 1994. Evaluation of chronic neurological sequelae after acute pesticide exposure using SPECT brain scans. J. Toxicol. Environ. Health 41, 275-284.

Cole, D.C., Carpio, F., Julian, J., Leon, N., Carbotte, R., De Almeida, H., 1997. Neurobehavioral outcomes among farm and non farm rural Ecuadorians. Neurotoxicol. Teratol. 19, 277-286.

Corrigan, F.M., MacDonald, S., Brown, A., Armstrong, K., Armstrong, E.M., 1994. Neurasthenic fatigue, chemical sensitivity and GABAa receptor toxins. Med. Hypotheses 43, 195-200.

Davies, D.R., Ahmed, G.M., Freer, T., 1999. Chronic organophosphate induced neuropsychiatric disorder (COPIND): results of two postal questionnaire surveys. J. Nutr. Environ. Med. 9, 123-134.

Dille, J.R., Smith, P.W., 1964. Central nervous system effects of chronic exposure to organophosphate insecticides. Aerosp. Med. 35, 475-478.

Duffy, F.H., Burchfiel, J.L., 1980. Long term effects of the organophosphate sarin on EEG in monkeys and humans. Neurotoxicology 1, 667-689.

Duffy, F.H., Burchfiel, J.L., Bertels, P.H., Gaon, M., Sim, V.M., 1979. Long term effects of an organophosphate upon human EEG. Toxicol. Appl. Pharmacol. 47, 161-176. 
Eckberg, D.L., White, C.W., Kioschos, J.M., Abboud, F.M., 1974. Mechanisms mediating bradycardia during coronary arteriography. J. Clin. Invest. 54, 1455-1461.

Fiedler, N., Kipen, H., Kelly-McNeil, K., Fenske, R., 1997. Long term use of organophosphates and neuropsychological performance. Am. J. Indust. Med 32, 487-496.

Gershon, S., Shaw, F.B., 1961. Psychiatric sequelae of chronic exposure to organophosphate insecticides. Lancet 1, 13711374.

Glynn, P., 2000. Non-cholinergic neurotoxicity induced by organophosphates: elucidation of molecular targets and mechanisms. Proceedings of Workshop on Organophosphates, Society of Chemical Industry. March 2000.

Hirschberg, A., Lerman, Y., 1984. Clinical problems in organophosphate insecticide poisoning. The use of a computerized information system. Fundam. Appl. Toxicol 4, 5209-5214.

Holms, J.H., 1955. Clinical studies of exposure to organophosphorus pesticides. In: Chichester, C.O. (Ed.), Research in Pesticides. Academic Press, New York.

Horowitz, S.H., Stark, A., Marshall, E., Mauer, M.P., 1999. A multimodality assessment of peripheral nerve function in organophosphate pesticide applicators. J. Occup. Environ. Med. 41, 405-408.

Jamal, G.A., 1997. Neurological syndromes of organophosphorus compounds. Adv. Drug React. Toxicol. Rev. 16, $133-170$.

Jamal, G.A., Hansen, S., Apartopoulos, F., Peden, A., Aziz, M.A., Ballantyne, J.P., 2001. Peripheral nerve dysfunction in farmers using organophosphate sheep dip. J. Nutr. Environ. Med. 11, 9-22.

Jordan, D., 1995. CNS integration of cardiovascular regulation. In: Jordan, D., Marshall, J. (Eds.), Cardiovascular Regulation. Portland Press, London, pp. 1-14.

Julu, P.O., Hansen, S., Jamal, G.A., 1997. Peripheral Nerve \& Autonomic Unit. Institute of Neurological Sciences, Glasgow, unpublished data.

Julu, P.O.O., Jamal, G.A., Hansen, S., Ballantyne, J.P., 1997a. Autonomic and neurophysiological features of chronic organophophate exposure. Clin. Autonomic Res. 7, 70.

Julu, P.O.O., McCarron, M.O., Hansen, S., Barnes, A., Jamal, G.A., Ballantyne, J.P., 1997b. Selective defect of baroreflex blood pressure buffering with intact cardioinhibition in a woman with familial aniridia. Neurology 49, 1705-1707.

Julu, P.O.O., McCarron, M.O., Hansen, S., Job, H., Jamal, G.A., Ballantyne, J.P., 2000. Complex regional pain syndrome with selective emotional sudomotor failure. [Case report]. Eur. J. Neurol. 7, 351-354.

Julu, P.O.O., Al-Rawas, S.F.S., Patel, D., Jamal, G.A., Shakir, R., 2001. Selective cutaneous vasoconstrictor and sudomotor failure associated with acute brainstem haemorrhage. Clin. Autonom. Res. 11 (2), 131-132.

Kaplan, J.G., Kessler, J., Rosenberg, N., Pack, D., Schaumberg, H.H., 1993. Sensory neuropathy associated with Dursban (chlorpyrifos) exposure. Neurology 43, 21932196.
Kelly, S.S., DeBlaquiere, G.E., Williams, F.M., Blain, P.G., 1997. Effects of multiple doses of organophosphates on evoked potentials in mouse diaphragm. Hum. Exp. Toxicol. $16,72-78$.

Kelly, S.S., Mutch, E., Williams, F.M., Blain, P.G., 1994. Electrophysiological and biochemical effects following single doses of organophosphates in the mouse. Arch. Toxicol. 68, 459-466.

Kilburn, K.H., 1999. Evidence for chronic neurobehavioral impairment from chlorpyrifos an organophosphate insecticide (Dursban) used indoors. Environ. Epidemiol. Toxicol. 1, 153-162.

Korsak, R.J., Sato, M.M., 1977. Effects of chronic organophosphate pesticide exposure on the central nervous system. Clin. Toxicol. 11, 83-95.

Levin, H.S., Rodnitzky, R.L., Mick, D.L., 1976. Anxiety associated with exposure to organophosphate compounds. Arch. Gen. Psychiat. 33, 225-228.

Maizlish, N., Schenker, M., Weisskopf, C., Seiber, J., Samuels, S., 1987. A behavioural evaluation of pest control workers with short-term, low-level exposure to the organophosphate diazinon. Am. J. Indust. Med. 12, 153-172.

McConnell, R., Keifer, M., Rosenstock, L., 1994. Elevated quantitative vibrotactile threshold among workers previously poisoned with methamidophos and other organophosphate pesticides. Am. J. Indust. Med. 25, 325-334.

Metcalf, D.R., Holmes, J.H., 1969. EEG, psychological and neurological alterations in humans with organophosphorus exposure. Ann. NY Acad. Sci. 160, 357-365.

Misra, U.K., Prasad, M., Pandey, C.M., 1994. A study of cognitive functions and event related potentials following organophosphate exposure. Electromyogr. Clin. Neurophysiol. 34, 197-203.

Moran, N., Delamont, R.S., Julu, P.O.O., 2001. Selective cardioaccelerator failure associated with a medullary sclerotic plaque in a fully conscious human subject. Clin. Autonom. Res. 11 (2), 133.

Parron, T., Hernandez, A.T., Villanueva, E., 1996. Increased risk of suicide with exposure to pesticides in an intensive agricultural area: a 12 year retrospective study. Forens. Sci. Int. 79 (1), 53-63.

Pilkington, A., Jamal, G.A., Gilham, R., et al., 1999. Epidemiological study of the relationships between exposure to organophosphate pesticides and indices of chronic peripheral neuropathy and neuropsychological abnormalities in sheep farmers and dippers. Phase 3; Clinical neurological, neurophysiological and neuropsychological study. Official report to British HSE, DoH and MAFF, May; pp. 1-205.

Prendergast, M.A., Terry, A.V., Buccafusco, A.J., 1997. Chronic low level exposure to diisopropylfluorophosphate causes protracted impairment of spatial navigation learning. Psychopharmacology 129, 183-191.

Rodnitzky, R.L., Levin, H.S., Mick, D.L., 1975. Occupational exposure to organophosphate pesticides. A neurobehavioural study. Arch. Environ. Health 30, 98-103.

Rosenstock, L., Keifer, M., Daniell, W.E., McConnell, R., Claypoole, K., 1991. Chronic central nervous system effects 
of acute organophosphate pesticide intoxication. Lancet $338,223-227$.

Savage, E.P., Keefe, T.F., Mounce, L.M., Heaton, R.K., Lewis, J.A., Burcar, P.J., 1988. Chronic neurological sequelae of acute organophosphate pesticide poisoning. Arch. Environ. Health 43, 38-45.

Steenland, K., Jenkins, B., Ames, R.G., O’Malley, M., Chrislip, D., Russo, J., 1994. Chronic neurological sequelae to organophosphate pesticide poisoning. Am. J. Public Health 84, 731-736.

Stephens, R., Spurgeon, A., Calvert, I.A., Beach, J.R., Levy, L.S., Berry, H., Harrington, M., 1995. Neuropsychological effects of long-term exposure to organophosphates in sheep dip. Lancet 345, 1135-1139.

Stokes, L., Stark, A., Marshall, E., Narang, A., 1995. Neurotoxicity among pesticide applicators exposed to organophosphates. Occup. Environ. Med. 52, 648-653.

Stoller, A., Krupinski, J., Christophers, A.J., Blanks, G.K., 1965. Organophosphate insecticides and major mental illness. Lancet 1, 1387-1388.

Tabershaw, I.R., Cooper, W.C., 1966. Sequelae of acute organic phosphate poisoning. J. Occup. Med. 8, 5-20. 